\title{
Resistência mecânica do solo à penetração em sistema silvipastoril após onze anos de implantação
}

\author{
Mechanical resistance to soil penetration in a silvipastoral system after eleven \\ years of implantation
}

\section{Laércio Ricardo SartorI, Jessica Ramão"II, Vanderley Porfírio da Silva" ${ }^{\mathrm{III}}$, Luis César Cassol ${ }^{\mathrm{IV}}$, Eleandro José Brun ${ }^{\mathrm{v}}$}

\begin{abstract}
Resumo
Com a crescente demanda por alimentos, surge a necessidade de intensificação no uso do solo, convergindo para sistemas de produção com características de sustentabilidade. Uma alternativa, aplicada à agricultura, é a adoção de sistemas integrados de produção agropecuária, como exemplo está o sistema silvipastoril. A integração entre sistemas de produções visa maximizar o uso dos recursos naturais e dos insumos, com menos impacto sobre o ambiente e maior ganho em produtividade da área. Nesse sentido, os efeitos em longo prazo, promovidos por sistemas silvipastoris nos atributos físicos do solo, devem ser estudados e relatados na literatura científica. O objetivo deste trabalho foi avaliar a resistência mecânica do solo à penetração (RMP) em faixas longitudinais distribuídas entre linhas de árvores plantadas em duas disposições, Leste-Oeste e Norte-Sul, de um solo sob um sistema silvipastoril após 11 anos de sua implantação. A espécie arbórea implantada em 2006 foi a Grevillea robusta e, como espécie forrageira, a Tifton 85 (Cynodon spp.) sob pastejo com lotação rotacionada de bovinos de leite. Para determinação da RMP foram avaliadas as camadas de solo de $0,0-0,05 ; 0,05-0,10 ; 0,10-0,20$ e $0,20-0,40 \mathrm{~m}$ de profundidade com auxílio de penetrômetro digital. Utilizou-se o delineamento experimental de blocos ao acaso. As disposições das árvores não foram consideradas como fator experimental e as análises feitas isoladamente dentro das disposições Leste-Oeste e Norte-Sul. Os maiores valores de RMP foram observados na camada de $0,05-0,10 \mathrm{~m}$ do solo e nas áreas avaliadas com maior proximidade das árvores, indicando o efeito do animal, que permanece nesses locais por mais tempo devido ao conforto térmico proporcionado pela sobra das árvores. A serapilheira depositada no solo pelas árvores e sistema radicular da espécie forrageira deve ter auxiliado para que os níveis de RMP fossem menores na superfície do solo, considerando o incremento nos teores de matéria orgânica na superfície do solo. O efeito do sistema radicular da espécie arbórea pode ter contribuído para os maiores valores de RMP na profundidade de 0,20 a $0,40 \mathrm{~m}$ para disposição LesteOeste.
\end{abstract}

Palavras-chave: Física do solo; Sistemas de produção sustentáveis; Silvicultura

\footnotetext{
Engenheiro Agrônomo, Dr., Professor da Coordenação do Curso de Agronomia, Universidade Tecnológica Federal do Paraná, Estrada Para Boa Esperança, Km 4, CEP 85660-000, Dois Vizinhos (PR), Brasil. laerciosartor@utfpr.edu.br (ORCID: 0000-0002-1615-6216)

Engenheira Florestal, Mestre pelo Programa de Pós Graduação em Agroecossistemas, Universidade Tecnológica Federal do Paraná, Estrada Para Boa Esperança, Km 4, CEP 85660-000, Dois Vizinhos (PR), Brasil. jessica.ramao@yahoo.com (ORCID: 0000-0003-2296-564X)

III Engenheiro Agrônomo, Dr., Pesquisador da Embrapa Florestas, Estrada da Ribeira, Km 111, Bairro Guaraituba, CEP 83411-000, Colombo (PR), Brasil. vanderley.porfirio@embrapa.br (ORCID: 0000-0002-7910-3680)

IV Engenheiro Agrônomo, Dr., Professor do Departamento Acadêmico de Ciências Agrárias, Universidade Tecnológica Federal do Paraná, Via do Conhecimento, Km 1, CEP 85503-390, Pato Branco (PR), Brasil. cassol@utfpr.edu.br (ORCID: 0000-0001-7852-0098)

Engenheiro Florestal, Dr., Professor da Coordenação do Curso de Engenharia Florestal, Universidade Tecnológica Federal do Paraná, Estrada Para Boa Esperança, Km 4, CEP 85660-000, Dois Vizinhos (PR), Brasil. eleandrobrun@utfpr.edu.br (ORCID: 0000-0003-3832-1320)
} 


\begin{abstract}
Along with the growing demand for food, the need arises for intensification in the land use, converging to production systems with sustainability characteristics. An alternative one, applied to agriculture, is the adoption of integrated systems of agricultural production like the silvipastoral system. The integration between production systems aims to maximize the use of natural resources and inputs, with less impact on the environment and greater productivity gain in the area. In this sense, the long-term effects promoted by silvipastoral systems on soil, the physical attributes should be studied and reported in the scientific literature. The objective of this work was to evaluate the mechanical resistance of the soil to penetration (RMP) in longitudinal strips distributed between rows of trees planted in two arrangements, East-West and North-South, of a soil under a silvipastoral system, after 11 years of its implementation. The tree species implanted in 2006 was Grevillea robusta and, as forage species, Tifton 85 (Cynodon spp.) under pasture with rotated dairy cattle. In order to determine the RMP, soil layers of $0.0-0.05 ; 0.05-0.10 ; 0.10-$ 0.20 and $0.20-0.40 \mathrm{~m}$ depth were evaluated using a digital penetrometer. The experimental design used was that of random blocks with three repetitions. The arrangement of the trees was not considered as an experimental factor and the analyses were made in isolation within the East-West and North-South arrangement. The results showed that the highest RMP values were observed in the $0.05-0.10 \mathrm{~m}$ layer and in the strips close to the trees, due to the greater permanence of the animals in these locations. The burlap deposited in the soil by the trees and the root system of the fodder species should have helped so that the levels of RMP were lower at the soil surface, considering the increase in organic matter contents at the soil surface. The effect of the root system of the tree species may have contributed to higher RMP values at depths of 0.20 to $0.40 \mathrm{~m}$ for east-west disposition.
\end{abstract}

Keywords: Soil physics; Sustainable production systems; Forestry

\title{
Introdução
}

A produção animal e vegetal pode trazer efeitos positivos ou negativos às propriedades físicas do solo, com possível aumento da compactação dos solos, seja em áreas onde são adotados sistemas conservacionistas, em sistemas de preparo convencional ou em solos ocupados com pastagens (ANDRADE; STONE; GODOY, 2013). Quanto mais agressivo é o sistema de produção ou devido à utilização de práticas inadequadas de manejo, maior é o reflexo nas propriedades físicas do solo (STEFANOSKI et al., 2013).

A degradação do solo é determinada por diferentes práticas de manejo do solo e uso do solo, refletindo na sustentabilidade dos agroecossistemas (OLIVEIRA et al., 2014). Entre os efeitos negativos ao solo está seu maior adensamento, gerando efeitos negativos nos seus atributos físicos, como porosidade e densidade do solo, sendo consequência da pressão a que é submetido, causando a redução do volume, aumento da densidade e, consequentemente, na resistência mecânica à penetração (OLIVEIRA et al., 2010). Com a compactação do solo tem-se limitação no desenvolvimento radicular das plantas, reduzindo crescimento e produtividade. Outro fato é que solos compactados alteram o comportamento da infiltração e escoamento das águas, podendo gerar erosão (KLEIN; KLEIN, 2014) e baixa capacidade de armazenamento de água.

Um aspecto atrelado à sustentabilidade da produção agropecuária é a degradação das pastagens, causada devido à baixa fertilidade do solo, compactação, declividade, pedregosidade ou limitações de drenagem. Sendo assim, para reduzir e buscar recuperar o solo de processos de degradação tornam-se eficazes os sistemas integrados de produção agropecuária, como a integração lavoura-pecuária e sistemas silvipastoris (PEZARICO et al., 2013).

Apesar da existência de estudos que comprovem a eficiência de uso da terra em áreas com sistemas integrados de produção agropecuária e florestal (SPERA et al., 2009; CONTE, 2011), algumas metodologias para seu estabelecimento são questionadas, como a distância entre renques de árvores, espécies arbóreas e forrageiras, tipo e qualidade da sobra, comportamento animal, disposição de linhas de árvores, sistema de uso da pastagem e manejo das espécies arbóreas, uma vez que todas essas variáveis podem estar relacionadas na variabilidade das condições físicas do solo, sendo a resistência mecânica do solo à penetração um possível indicativo do efeito do animal e da árvore sobre o sistema silvipastoril. Quando o manejo é inadequado, tem-se efeitos sobre os atributos físicos do solo através 
da deformação da estrutura do solo, densidade, tamanho e quantidade dos poros (CORRÊA, 2013), o que caracteriza a capacidade do solo em armazenar água e condicionar o desenvolvimento radicular das culturas.

Contudo, o adensamento do solo,advindo de animais em pastejo nos sistemas silvipastoris, determina a reorganização do solo e esse comportamento segue um contexto de uma compactação benéfica, em que a planta é sujeita a um estresse moderado, ativador e estimulador, causando efeito positivo para seu desenvolvimento (ANGHINONI et al., 2015). Sendo assim, a avaliação da qualidade física do solo é uma variável que pode auxiliar na escolha do manejo e técnica apropriada no âmbito de uma agricultura sustentável, além disso, são escassas as informações dos efeitos das árvores sobre os atributos físico do solo em sistemas silvipastoris.

Sendo assim, este trabalho teve como objetivo avaliar a resistência mecânica do solo à penetração de um solo sob sistema silvipastoril após onze anos de sua implantação, nas áreas próximas às árvores, nas entrelinhas das árvores e em quatro diferentes camadas do solo.

\section{Material e método}

O trabalho foi realizo no município de Saudade do Iguaçu - Paraná, $25^{\circ} 43$ ’57”S, 52³5’39”W e a 590 metros de altitude. O clima da região é subtropical úmido mesotérmico Cfa, as características são: verão quente e geadas pouco frequentes, sem ter estação seca definida. As temperaturas médias são superiores a $22^{\circ} \mathrm{C}$ nos meses mais quentes e inferiores a $18^{\circ} \mathrm{C}$ nos meses mais frios (ALVARES et al., 2013). A área tem relevo suave ondulado e o solo classificado como Latossolo Vermelho distroférrico (EMBRAPA, 2018). A caracterização química do solo está representada na Tabela 1 e a composição granulométrica do solo foi de: $650 \mathrm{~g} \mathrm{~kg}^{-1}$ de argila, $170 \mathrm{~g} \mathrm{~kg}^{-1}$ de silte e $180 \mathrm{~g} \mathrm{~kg}^{-1}$ de areia.

\section{Tabela 1 - Histórico dos laudos de análise de solo, profundidade 0 a 0,2m da área experimental. Saudade do Iguaçu - PR}

Table 1 - History of soil analysis reports, depth 0 to $0.2 \mathrm{~m}$ from experimental area.

Saudade do Iguaçu - PR state

\begin{tabular}{lcccc}
\hline & & $\mathbf{2 0 0 7}$ & $\mathbf{2 0 1 0}$ & $\mathbf{2 0 1 1}$ \\
\hline $\mathbf{p H}$ & $\mathrm{CaCl}_{2}$ & 4,2 & 4,3 & 5,0 \\
$\mathbf{M O}$ & $\mathrm{g} \mathrm{dm}^{-3}$ & 46,91 & 26,6 & 60,31 \\
$\mathbf{H + A l}$ & $\mathrm{cmolcdm}^{-3}$ & 5,35 & 7,2 & 5,47 \\
$\mathbf{A l}$ & $\mathrm{cmolcdm}^{-3}$ & 0,71 & 0,47 & 0,00 \\
$\mathbf{C a}$ & $\mathrm{cmolc} \mathrm{dm}^{-3}$ & 3,90 & 2,71 & 5,73 \\
$\mathbf{M g}$ & $\mathrm{cmolcdm}^{-3}$ & 2,00 & 1,80 & 3,29 \\
$\mathbf{K}$ & $\mathrm{cmolcdm}^{-3}$ & 0,50 & 0,63 & 0,65 \\
$\mathbf{P}$ & $\mathrm{mg} \mathrm{dm}^{-3}$ & 8,55 & 4,58 & 25,85 \\
$\mathbf{V \%}$ & $\%$ & 54,47 & 41,65 & 63,87 \\
$\mathbf{S B}$ & $\mathrm{cmolcdm}^{-3}$ & 6,4 & 5,1 & 9,7 \\
SMP & - & 5,9 & 5,5 & 5,9 \\
CTC & $\mathrm{cmolcdm}^{-3}$ & 11,75 & 12,34 & 15,14 \\
Sat. Al & $\%$ & 9,99 & 8,38 & 0,00 \\
\hline
\end{tabular}

Fonte: Autores (2019) 
O sistema silvipastoril foi implantado em janeiro de 2006. Anteriormente, a área era utilizada para produção de grãos. A área totaliza 10,2 ha, com cultivo de grevílea (Grevillea robusta) como espécie arbórea e, como espécie forrageira a Tifton 85 (Cynodonspp,). Os animais são bovinos de leite da raça Jersey em cruzamento com animais da raça Holandês Vermelho. No período hibernal, em alguns anos, fez-se a sobressemeadura de espécies anuais de inverno (como aveia e/ou azevém) sobre a pastagem de Tifton 85 , portanto a pastagem é utilizada durante todo o ano. A pastagem é manejada através de um sistema de pastejo com lotação rotacionada.

O total de árvores no sistema, em 2006, era de 2.550 indivíduos, sendo aproximadamente 250 árvores $\mathrm{ha}^{-1}$, plantadas em nível e distribuídas em linhas simples distanciadas 20 metros e com 2 metros entre árvores, na linha. Em 2014, foi realizado um desbaste, retirando-se 70 árvores ha $^{-1}$, restando 180 árvores ha ${ }^{-1}$. Com base na disposição das linhas de árvores, convencionaramse avaliações em Leste-Oeste e Norte-Sul, essas não foram consideradas como tratamento, as repetições foram dentro de cada disposição de árvore e, portanto, fizeram-se análises separadas, uma para cada disposição de árvores, uma vez que a coleta das variáveis de RMP não foi feita no mesmo dia, o que apresenta variação devido à umidade do solo.

Foram demarcadas áreas amostrais em cada disposição de árvores, considerando uma distribuição de renques de árvore no sentido Leste-Oeste e outra no sentido Norte-Sul. Em cada área foram alocados três blocos de $20 \mathrm{~m} \times 20 \mathrm{~m}$, estabelecidos entre os renques de árvores. Para cada bloco foi formado um grid composto por 25 quadrantes de $4 \mathrm{mx} 4 \mathrm{~m}$. Em cada quadrante foi coletada uma amostragem de RMP. Foram determinadas cinco faixas paralelas às linhas das árvores, cada faixa compõe um tratamento a fim de determinar a RMP presente nos mosaicos de sombra formados entre as linhas de árvores.

Após a demarcação das parcelas e dos pontos a serem amostrados, foi feita a medição da RMP considerando a média de quatro profundidades: 0-0,05; 0,05-0,10; 0,10-0,20 e 0,20-0,40 m. Foi utilizado um penetrômetro digital da marca FALKER modelo Penetro LOG-PLG 1020, configurado para registrar leituras a cada $0,01 \mathrm{~m}$ de, em $\mathrm{KPa}$, posteriormente os resultados obtidos foram multiplicados pela constante 0,0980665 para transformação em MPa, conforme Beutleret al. (2001).

Foi coletada uma amostra de solo em cada faixa nas mesmas profundidades em que se determinou a RMP para determinação da umidade gravimétrica (EMBRAPA, 1997). As amostras de solo, para cada disposição, foram coletadas em datas distintas, sendo realizada em 21/04/16 para disposição Leste-Oeste e 19/07/16 para disposição Norte-Sul, sendo $24,20 \%$ e 33\%, respectivamente.

Por fim, as extremidades de cada bloco foram georreferenciadas com GPS geodésico modelo GTR $G^{2}$. A partir dos pontos de controle foi realizado o transporte de coordenadas para os demais pontos da parcela, para que posteriormente fosse desenvolvido os mapas de RMP através do software livre ArcGIS. No software ArcGis foram inseridos os dados de RMP e de localização espacial dos pontos de coleta. Com o modelo definido através do software $\mathrm{R}$, o método de interpolação por krigagem ordinária pode ser aplicado. Foi realizada a interpolação para todos os conjuntos de dados das diferentes camadas de solo dentro de cada disposição de linhas de árvores. Após a interpolação dos pontos amostrados, foram criados mapas para as camadas de solo 0,00 a $0,05 \mathrm{~m} ; 0,05$ a $0,10 \mathrm{~m} ; 0,10$ a $0,20 \mathrm{~m}$ e 0,20 a $0,40 \mathrm{~m}$. Para cada camada de solo considerou-se a média da RMP aferida a cada $0,01 \mathrm{~m}$ de profundidade.

O experimento foi avaliado com delineamento experimental de blocos ao acaso em três repetições e cinco tratamentos. Os tratamentos são representados pelas faixas de amostragem, que estão no sentido dos renques. Os resultados de cada disposição foram submetidos a análises de variância pelo teste $\mathrm{F}$ a um nível de significância de $5 \%$ de probabilidade e, posteriormente, as médias foram comparadas pelo teste Tukey a 5\% de probabilidade de erro. Empregou-se o programa computacional Statgraphics para análise dos dados. 


\section{Resultados e discussão}

Nas duas disposições de linhas de árvores, observou-se que não houve diferença entre as faixas avaliadas na camada de 0 a $0,05 \mathrm{~m}$ (Figura 1) para a RMP. Na superfície do solo é maior a quantidade de material acrescido ao solo através da senescência das folhas das árvores e do sistema radicular da pastagem cultivada, portanto, forma-se uma manta de serapilheira, raízes e massa de forragem das espécies envolvidas, o que resulta em uma menor RMP em camadas mais superficiais do solo (CARVALHO; GOEDERT; ARMANDO, 2004). Foi observado, entre os anos de 2006 a 2011, aumento da matéria orgânica do solo na camada 0 a 0,20m (Tabela 1).

Figura 1 - RMP do solo em quatro diferentes profundidades $(0,0-0,05 ; 0,05-0,10 ; 0,10-0,20$ e 0,020-0,040m) sob sistema silvipastoril. Disposição 1: Leste-Oeste e Disposição 2: Norte-Sul Barras não coincidentes dentro de cada profundidade diferem entre si pelo teste de Tukey a $5 \%$ de probabilidade de erro

Figure 1 - RMP of the soil at four different depths $(0,0-0,05 ; 0,05-0,10 ; 0,10-0,20$ e $0,020-0,040 \mathrm{~m})$ under silvopastoral system. Disposition 1: East-West; Layout 2: North-South, Non-coincident bars within each depth differ from each other by the Tukey test at $5 \%$ error probability

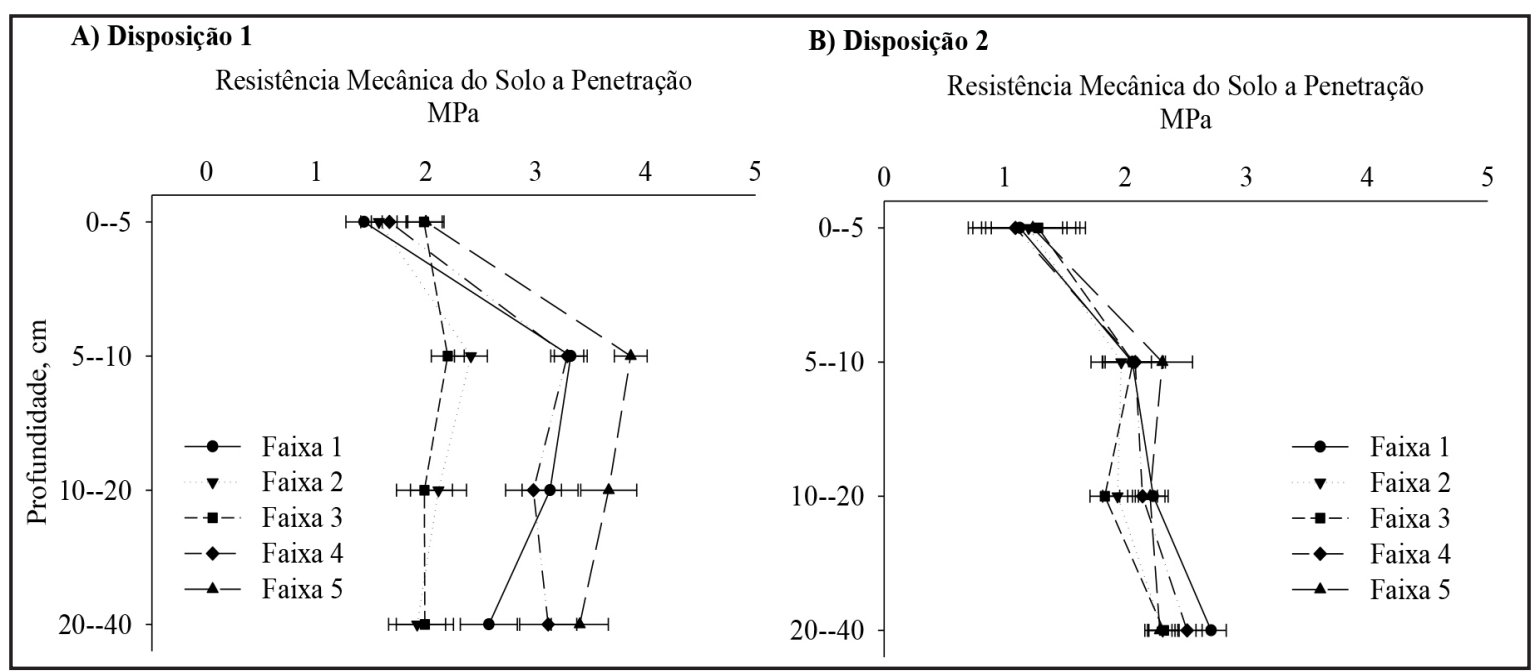

Fonte: Autores (2019)

Nota: Umidade do Solo: Disposição 1 = 24,20\%; Disposição 2 = 33\%

Ao analisar a distribuição espacial da RMP (Figura 2), observou-se baixa variabilidade na camada superficial, corroborando com os dados da Figura 1. Os maiores valores para RMP foram encontrados na disposição de árvores Leste-Oeste, na profundidade de 0,05 a $0,10 \mathrm{~m}$, nas áreas próximas as árvores (Figura 3), os valores altos de RMP nas faixas mais sombreadas devese, provavelmente, à presença dos animais por mais tempo nesses locais, sendo assim a elevada pressão exercida pelo casco do animal sobre o solo faz com que a geometria dos agregados seja alterada, devido ao esmagamento das partículas (ANDREOLLA, 2010). 
Figura 2 - Distribuição espacial da RMP na camada 0 a $0,05 \mathrm{~m}$ de profundidade em um sistema silvipastoril. A - As linhas das árvores estão dispostas no sentido Leste-Oeste; B As linhas das árvores estão dispostas no sentido Norte-Sul. Saudade do Iguaçu-PR

Figure 2 - Spatial distribution of PMR in layer 0 to $0.05 \mathrm{~m}$ depth in a silvopastoral system. A The tree lines are arranged east-west; B - The tree lines are arranged north-south. Saudade do Iguaçu-PR state

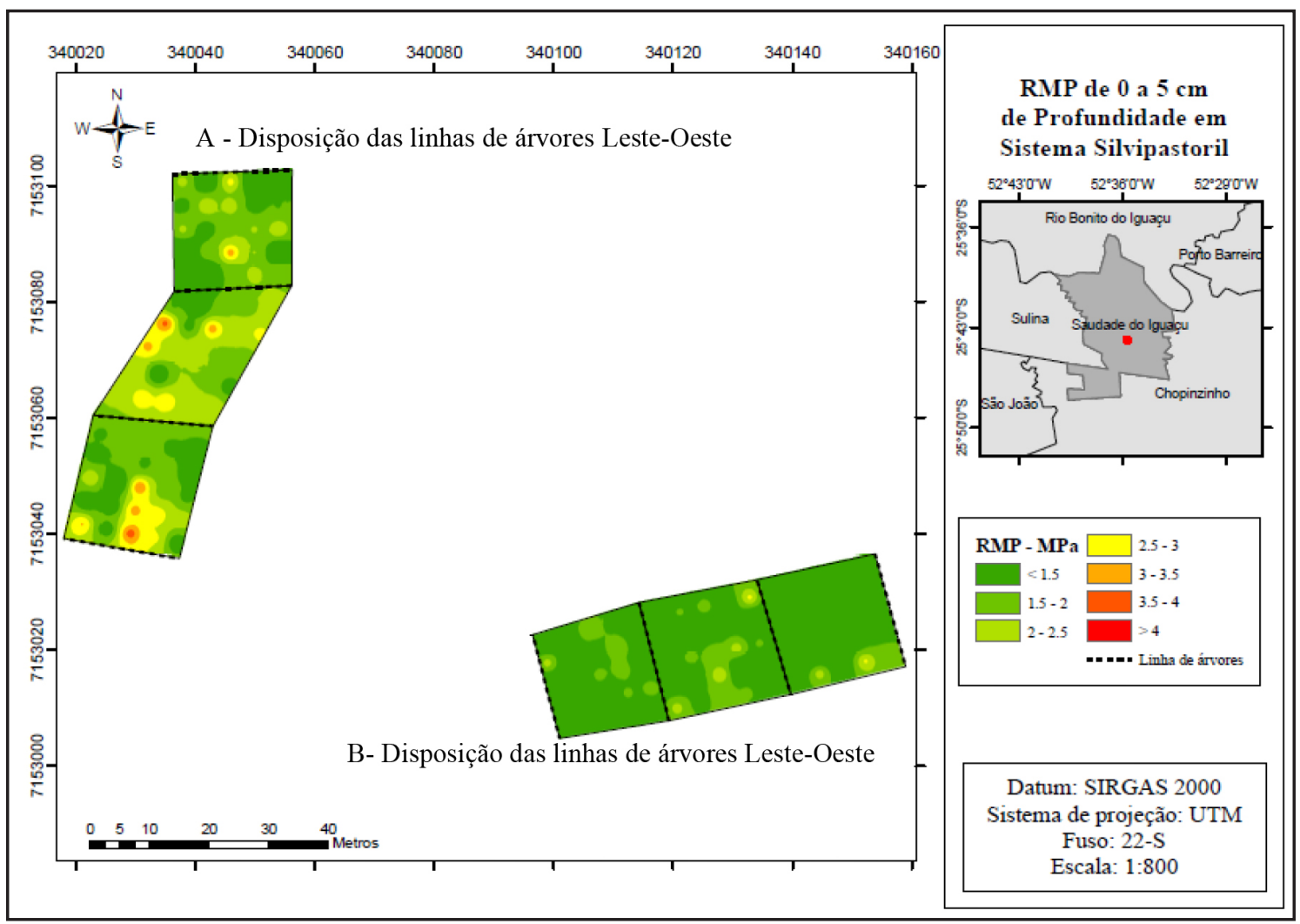

Fonte: Autores (2019)

Para Imhoffet et al. (2000), a proporção e o tipo das mudanças ocorridas nos atributos físicos do solo, devido à presença de animais em pastejo, são dependentes da carga animal, além da umidade e do tipo de solo. Considerando que o solo com alto teor de argila, como deste trabalho, maior é a suscetibilidade à compactação o que pode influencia na maior RMP encontrada em camadas superficiais do solo.

É possível também que, com altos teores de argila, maior a profundidade a qual a pressão é transmitida, aumentado a espessura da camada compactada (RICHART et al., 2005), assim, solos com textura média a argilosas apresentam maior suscetibilidade a manutenção da qualidade física do solo (STEFANOSKI, 2013). 
Figura 3 - Distribuição espacial da RMP na camada 0,05 a 0,10 m de profundidade em um sistema silvipastoril. A - As linhas das árvores estão dispostas no sentido Leste-Oeste; B As linhas das árvores estão dispostas no sentido Norte-Sul. Saudade do Iguaçu-PR

Figure 3 - Spatial distribution of PMR in layer 0.05 to $0.10 \mathrm{~m}$ depth in a silvopastoral system. A - The tree lines are arranged east-west; B - The tree lines are arranged north-south. Saudade do Iguaçu-PR state

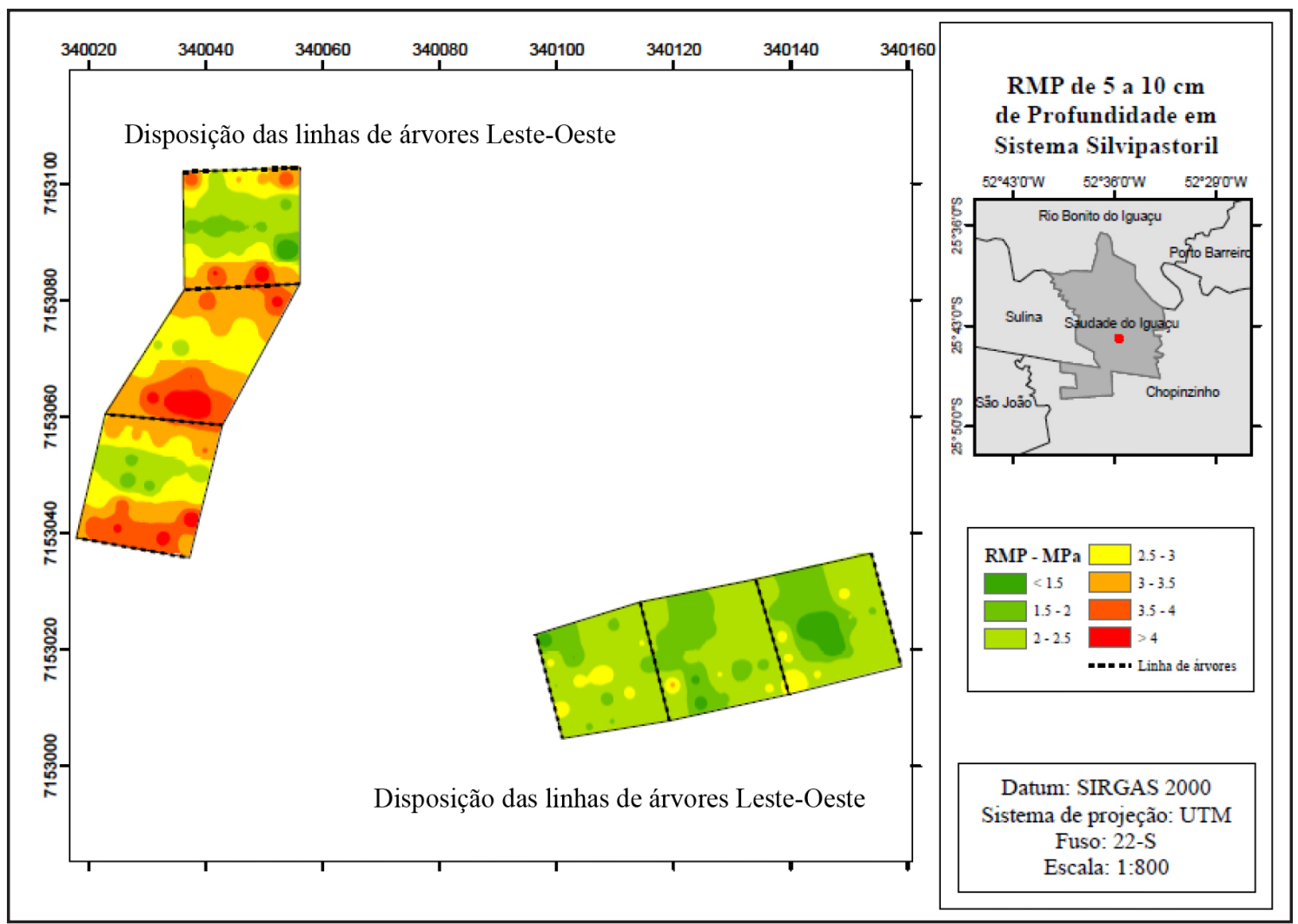

Fonte: Autores 2019

A maior RMP nas áreas próximas às linhas de árvores também é verificada na camada de 0,10 a 0,20 m (Figuras 1 e 4) para disposição de linhas de árvores no sentido Leste-Oeste, com maior RMP para faixas 1, 4 e 5 (faixas próximas das linhas de árvores) em relação às faixas 2 e 3 (faixas ao centro dos renques de árvores). Justifica-se esse resultado devido a maior concentração de animais nas áreas de maior sombreamento, mesmo com o controle da lotação de animais, com ajuste da carga animal conforme disponibilidade de forragem os animais permanecem boa parte do tempo em áreas de maior conforto térmico. Esse comportamento contribuiu com a elevação da resistência do solo à penetração, e embora as faixas um e cinco apresentem elevada quantidade de serapilheira, esses resíduos não foram suficientes para minorar o impacto promovido pelo pisoteio animal. Por um lado, existe o efeito negativo sobre a pastagem, contudo o ganho com o conforto térmico e com a ciclagem de nutrientes para próximo das árvores pode trazer maior produtividade de leite e madeira, aumentando a produção do sistema adotado.

A permanência por maior tempo dos animais nas áreas de sombra ou sobre a copa das árvores pode caracterizar menor produção de forragem e desenvolvimento das pastagens (DIAS FILHO, 2006), reduzindo o efeito que a espécie forrageira pode conferir ao solo ao proporcionar maior resiliência estrutural. Considerando a distribuição das linhas de árvores ser em LesteOeste, as sombras das árvores ficam concentradas nas faixas 1 e 5, enquanto que para a disposição Norte-Sul, a sombra se distribui por toda a pastagem durante o dia. 
Figura 4 - Distribuição espacial da RMP na camada 0,10 a 0,20 m de profundidade em um sistema silvipastoril. A - As linhas das árvores estão dispostas no sentido Leste-Oeste; B As linhas das árvores estão dispostas no sentido Norte-Sul. Saudade do Iguaçu-PR

Figure 4 - Spatial distribution of PMR in layer 0.10 to $0.20 \mathrm{~m}$ depth in a silvopastoral system. A - The tree lines are arranged east-west; B - The tree lines are arranged north-south. Saudade do Iguaçu-PR state

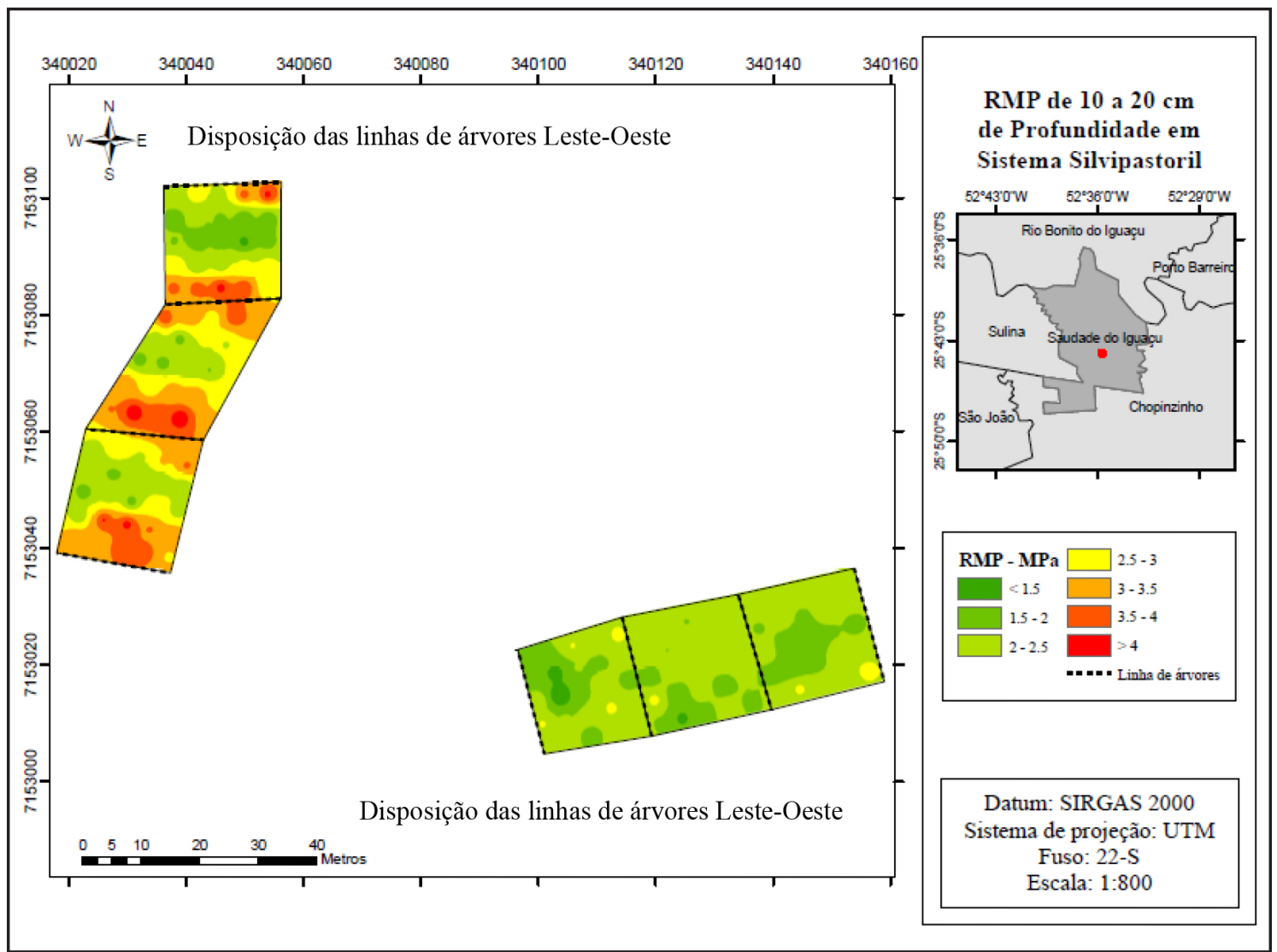

Fonte: Autores (2019)

$\mathrm{Na}$ camada do solo de 0,20 a $0,40 \mathrm{~m}$ (Figura 5), verificam-se resultados semelhantes aos encontrados nas camadas mais superficiais do solo, com destaque para disposição LesteOeste das linhas de árvores, onde os maiores valores de RMP foram encontrados nas áreas de solo próximas das árvores. Como menor intensidade, o mesmo comportamento foi encontrado na disposição Norte-Sul, confirmando o efeito do sistema radicular da espécie arbórea no adensamento do solo em camadas mais profundas. Vogel e Fey (2016) verificaram maior RMP do solo nas camadas abaixo de $0,2 \mathrm{~m}$ no sistema silvipastoril, atribuindo ao crescimento radicular das espécies arbóreas que tendem a comprimir o solo em maiores profundidades. 
Figura 5 - Distribuição espacial da RMP na camada 0,20 a 0,40 $\mathrm{m}$ de profundidade em um sistema silvipastoril. A - As linhas das árvores estão dispostas no sentido Leste-Oeste; B As linhas das árvores estão dispostas no sentido Norte-Sul. Saudade do Iguaçu-PR

Figure 5 - Spatial distribution of PMR in layer 0.20 to $0.40 \mathrm{~m}$ depth in a silvopastoral system. A - The tree lines are arranged east-west; B - The tree lines are arranged north-south. Saudade do Iguaçu-PR state

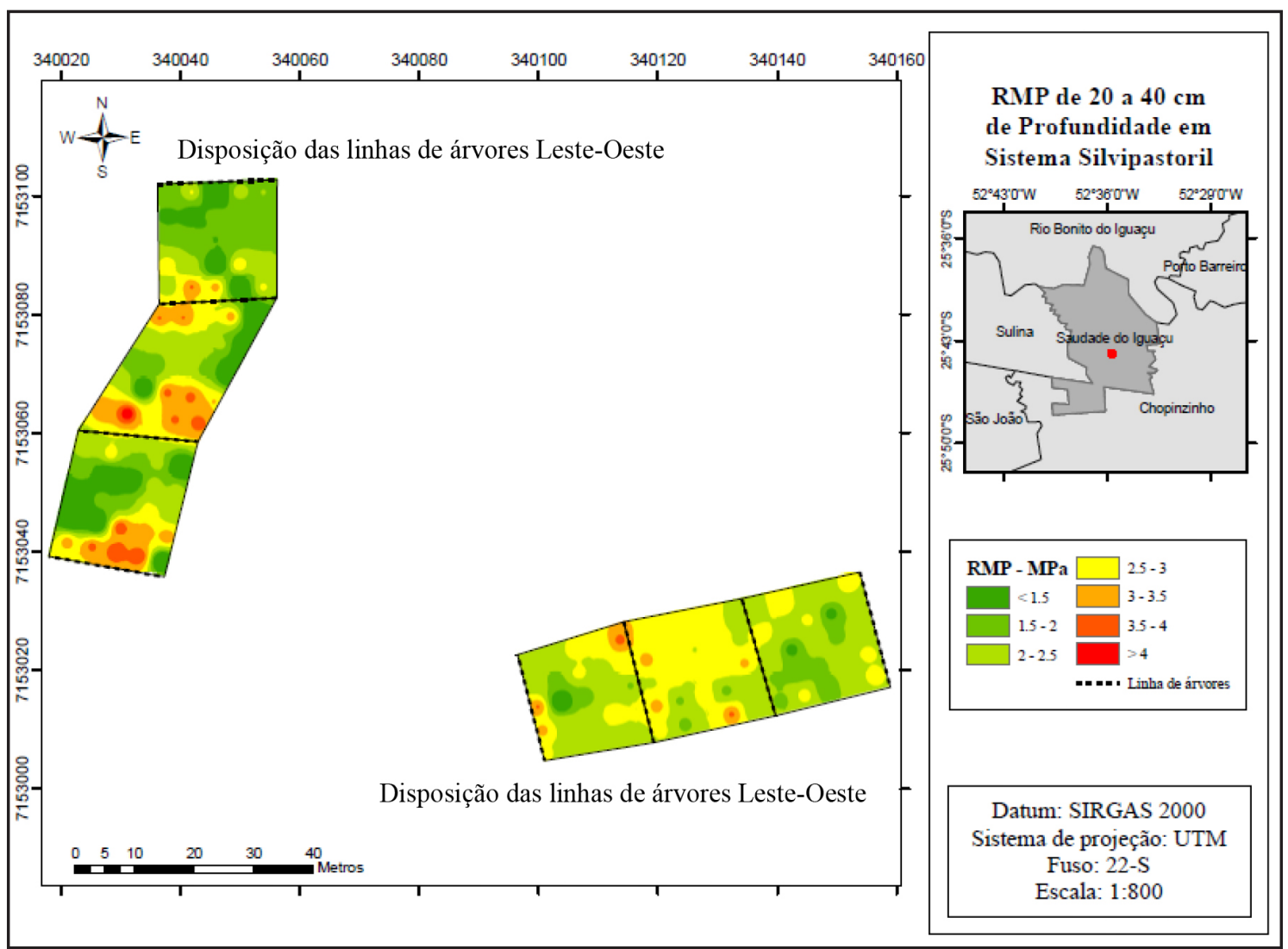

Fonte: Autores (2019)

Observa-se que na disposição Norte-Sul foi maior a RMP na profundidade de 0,20-0,40 nas faixas próximas dos renques de árvores e também na área central aos renques, o que pode estar relacionado às condições de adensamento natural do solo, devido às pressões promovidas pelas camadas superiores sobre as subjacentes. Esses resultados foram observados de maneira semelhante no trabalho de Martinkoskiet et al. (2017), onde foi aumentada a RMP com o aumento da profundidade em avaliações de áreas de sistema silvipastoril. 


\section{Conclusão}

A RMP é maior nas áreas próximas das árvores, indicando efeito dos animais sobre as propriedades físicas do solo nos locais com mais sombra.

A RMP é menor na camada superficial do solo de 0 a $0,05 \mathrm{~m}$.

Em profundidade do solo de 0,20 e 0,40 m é maior a RMP, indicando efeito do sistema radicular da espécie arbórea.

\section{Agradecimentos}

A Capes - Coordenação de Aperfeiçoamento de Pessoal de Nível Superior, Universidade Tecnológica Federal do Paraná, Embrapa Florestas, Emater Paraná e IAPAR pelo apoio e auxílio na realização desse trabalho.

\section{Refêrencias}

ALVARES, C. A.etal. Köppen's climate classification map for Brazil. MeteorologischeZeitschrift, Stuttgart, v. 22, n. 6, p. 711-728, 2013.

ANDRADE, R. da S.; STONE, L. F.; GODOY, S. G. Estimativa da resistência do solo à penetração baseada no índice $S$ e no estresse efetivo. Revista Brasileira de Engenharia Agrícola e Ambiental,Campina Grande, v. 17, n. 9, p. 932-937, 2013.

ANDREOLLA, V. R. M. Integração lavoura-pecuária: atributos físicos do solo e produtividade das culturas do feijão e milho.2010. Tese (Doutorado em Agronomia) - Universidade Federal do Paraná, Curitiba, 2010.

ANGHINONI, I. et al. O solo no contexto. In: GRUPO DE PESQUISA EM SISTEMA INTEGRADO DE PRODUÇÃO AGROPECUÁRIA. Integração soja-bovino de corte no sul do Brasil. Porto Alegre, [s. n.], 2015. p. 53-72.

BEUTLER, A. N. et al. Resistência à penetração e permeabilidade de Latossolo Vermelho distrófico típico sob sistemas de manejo na região dos cerrados. Revista Brasileira de Ciência do Solo, [s. l.], v. 25, n. 1, p. 167-177, 2001.

CARVALHO, R.; GOEDERT, W. J.; ARMANDO, M. S. Atributos físicos da qualidade de um solo sob sistema agroflorestal. Pesquisa Agropecuária Brasileira,Brasília, v. 39, n. 1, p. 1153-1155, 2004.

CONTE, O. et al. Evolução de atributos físicos de solo em sistema de integração lavoura-pecuária. Pesquisa Agropecuária Brasileira, Brasília, v. 46, n. 10, p. 1301-1309, 2011.

CORREAA, A. R. Aspectos do sistema silvipastoril correlacionados com atributos de um neossoloquartzarênico em Mato Grosso do Sul. 2013. Dissertação (Mestrado em Agronomia) Universidade Estadual de Mato Grosso do Sul, Aquidauana, 2013.

EMBRAPA. Manual de Métodos de Análise de Solos. Rio de Janeiro, RJ, Embrapa,Centro Nacional de Pesquisa de Solos, 1997. 23.p

EMBRAPA. Sistema Brasileiro de Classificação de Solos. Brasília, DF: EMBRAPA Solos; 
Ministério da Agricultura, Pecuária e Abastecimento, 2018. Disponível em: https://www. embrapa,br/solos/sibcs/classificacao-de-solos. Acesso em: 17 dez. 2018.

IMHOFF, S.; SILVA, A. P. da.; TORMENA, C. A. Aplicações da curva de resistência no controle da qualidade física de um solo sob pastagem. Pesquisa Agropecuária Brasileira. Brasília. v. 35, n. 7, p. 1493 - 1500, 2000.

KLEIN, C.; KLEIN, V. A. Influência do manejo do solo na infiltração de água, Revista Monografias Ambientais, Santa Maria, v. 13, n. 5, p. 3915-3925, 2014,

MARTINKOSKI, L. I. etal.Qualidade física do solo sob manejo silvipastoril e floresta secundária. Floresta e Ambiente,Seropédica, v. 24, p. 1-9, 2017.

OLIVEIRA, A. P. P. de. et al. Sistemas de colheita da cana-de-açúcar: conhecimento atual sobre modificações em atributos de solos de tabuleiro. Revista Brasileira de Engenharia Agrícola e Ambiental,Campina Grande, v. 18, n. 9, p. 939-947, abr. 2014.

OLIVEIRA, V. S. et al. Compactação de um Argissolo Amarelo distrocoeso submetido a diferentes manejos. Revista Brasileira de Engenharia Agrícola e Ambiental, Campina Grande, v. 14, n. 9, p. $914-920,2010$.

PEZARICO, C. R.et al. Indicadores de qualidade do solo em sistemas agroflorestais. Revista de Ciências Agrárias, Belém, v. 56, n. 1, p. 40-47, 2013.

RICHART, A. et al. Compactação do solo: causas e efeitos. Semina: Ciências Agrárias,Londrina, v. 26, n. 3, p. 321-344, 2005.

SPERA, T. S. etal.Integração lavoura e pecuária e os atributos físicos de solo manejado sob sistema plantio direto. Revista Brasileira de Ciência do Solo, Viçosa, MG, v. 33, n. 1, p. 129-136, 2009.

STEFANOSKI, D. C. et al. Uso e manejo do solo e seus impactos sobre a qualidade física. Revista Brasileira de Engenharia Agrícola e Ambiental, Campina Grande, v. 17, n. 12, p. 1301-1309, 2013.

VOGEL, G. F.; FEY, R. Resistência mecânica à penetração em diferentes sistemas de uso do solo. Revista de Agricultura Neotropical, Cassilândia, v. 3, n. 1, p. 21-26, 2016. 